\title{
Design and Control of Single-stage LEDConverter with High Power Factor
}

\author{
Geun-Yong Park and Gang-YoulJeong* \\ Soonchunhyang University \\ *gangyoul@sch.ac.kr
}

\begin{abstract}
This paper presents a single-stage LED converter with high power factor. The proposed converter utilizes a single-stage power circuit that combinesthe boost DC-DC converter topology and theflyback converter topology. The control of the proposed converter operates using critical conduction mode and fixed on-time voltage control techniques. In this way the proposed converter is much simpler than currentconventional LED converters. An operational principle and a design example of the proposed converter are explained, briefly. Also, it is shown through experimental results that the proposed converter built based on the design example has good performance for driving LEDs.
\end{abstract}

Keywords: Single-stage, LED converter, high power factor, critical conduction mode, fixed on-time

\section{Introduction}

As light-emitting diodes (LEDs) have many advantages such as small size, high luminous efficiency, long lifetime, fast response, and excellent color rendering, they have been widely used in many lighting applications. LEDs are environmentally friendly devices compared with conventional fluorescent lamps that require mercury and may produce pollution. Therefore, in pursuit of energy-saving and pollution free light sources, LEDs have gradually replaced fluorescent lamps and have become increasingly and more widely used [1-8].

Asswitching-mode AC-DC converters have many advantages such as high energyconversion efficiency, high power density, and high control accuracy, they have been adopted as LED-driving converters that use a utility AC input.Conventionally, an AC-DC converter uses a bridge-diode rectifier and a bulky capacitor to obtain a nearly constant DC-link voltage for the next high-frequency DC-DC converter stage. Such an LED converter inevitably introduces a highly distorted AC input current due tothe large amount of harmonics resulting in a low power factor. To comply with the stringent regulation on current harmonics such as IEC-61000-3-2 class C and to improve the power factor, an additional AC-DC conversion stage is needed to cascade in front of the DC-DC converter to perform the function of power factor correction (PFC). Thisleads to a double-stage approach which is composed of a PFC stage to make the input current sinusoidal and a DC-DC conversion stage to regulate the output voltage [9-11].

The double-stage approaches have advantages in that it can easily obtain a high power factor and low harmonic distortion, alsothey can be designed optimally to includeenough time for energy accumulation. However, because the double-stage approaches utilize independent controllers for the PFC stage and the DC-DC converter stage, its control circuit becomes complicated, and thus their implementation cost is high. Also, because they must process 
power-conversions twice, their total efficiency is lower. Recently, many single-stage AC/DC converters have been developed [12-16].

The single-stage approaches have been derived by merging the boost DC-DC converter and the flyback converter. By sharing one active power switch and the control circuit, the single-stage approaches have advantages such as a simple circuit configuration, ease of control implementation and are cost-effective solution. Therefore, recently, the single-stage approaches for driving of LEDshav been widely utilized in general lighting applications.

In this paper, a single-stage LED converter with high power factor is presented. A DC-DC boost converter and a flyback converter are combined into a single-stage power conversion circuit. The proposed converter is controlled using the critical conduction mode technique and the fixed on-time voltage control technique. Therefore the total circuit of the proposed converter is very simple and small. The proposed converter offers a high power factor, high efficiency, cost-effectiveness, and constant output voltage/current. In this paper, an operational principle and a design example of the proposed converter are described, briefly, and experimental results of a prototype are shown. A 32-W prototype converter has been built based on the design example and tested to show the feasibility of the proposed converter. The prototype shows very good performance.

\section{Operational Principle of the Proposed Converter}

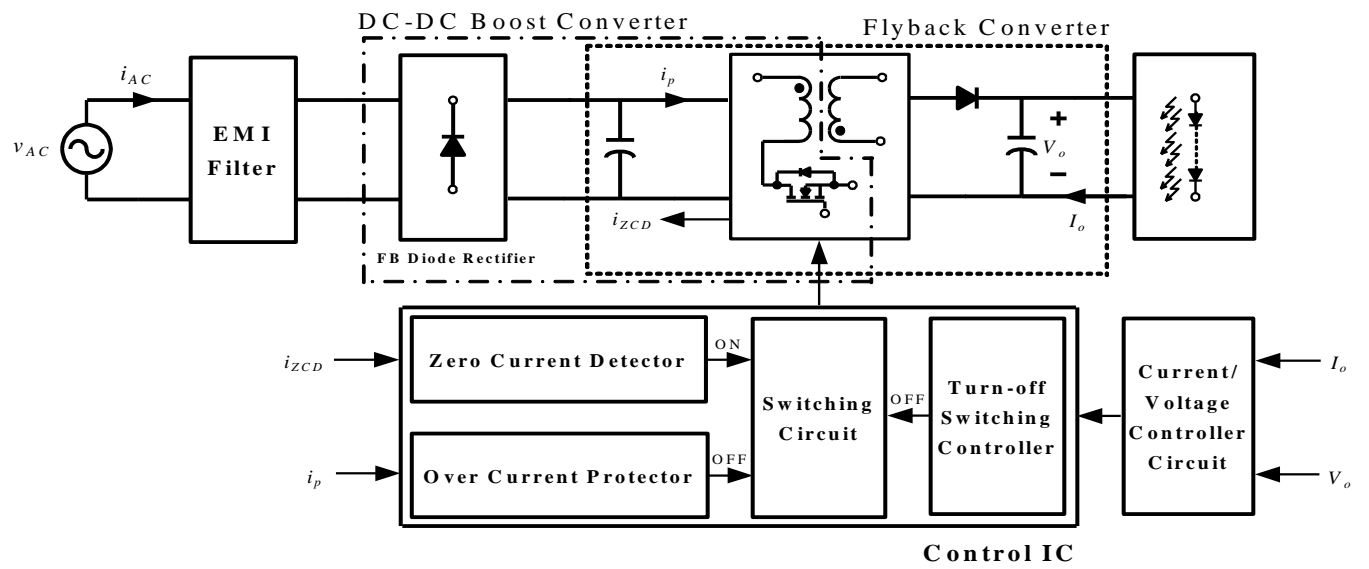

Figure 1. Conceptual Block Diagram of the proposed Converter

Figure 1 shows aconceptual block diagram of the proposed converter. The proposed converter is composed of a power circuit and a control circuit. The power circuit includes an electro-magnetic interference (EMI) filter, Full-bridge (FB) diode rectifier, single-stage converter, and LED load. The single-stage converter is a merged converter which comprises the DC-DC boost converter and the flyback converter. Asthe proposed converter uses a single-stage power topology, it can be simplified. The flyback converter operates with high frequency and controls the power flow using only one power semiconductor switch. This allows miniaturization and a lightweight construction. However,the AC input current of the flyback converter without any measures includes many harmonics due to the nonlinear operation of the FB diode rectifier connected at the AC input stage, as suchthe rectifier deteriorates the total harmonicdistortion (THD). In order to overcome these shortcomings, the proposed converter owns a transformer and power semiconductor switch jointly and connects the DC-DC boost converter in front of the flyback converter. Thus the proposed converter achieves a single-stage converter structure. The proposed converter is simpler than 
conventional LED converters, which are generally double-stage converters composed of a PFC stage and a DC-DC buck converter stage. So implementation costsare lower and it is simpler than conventional double-stage converters.

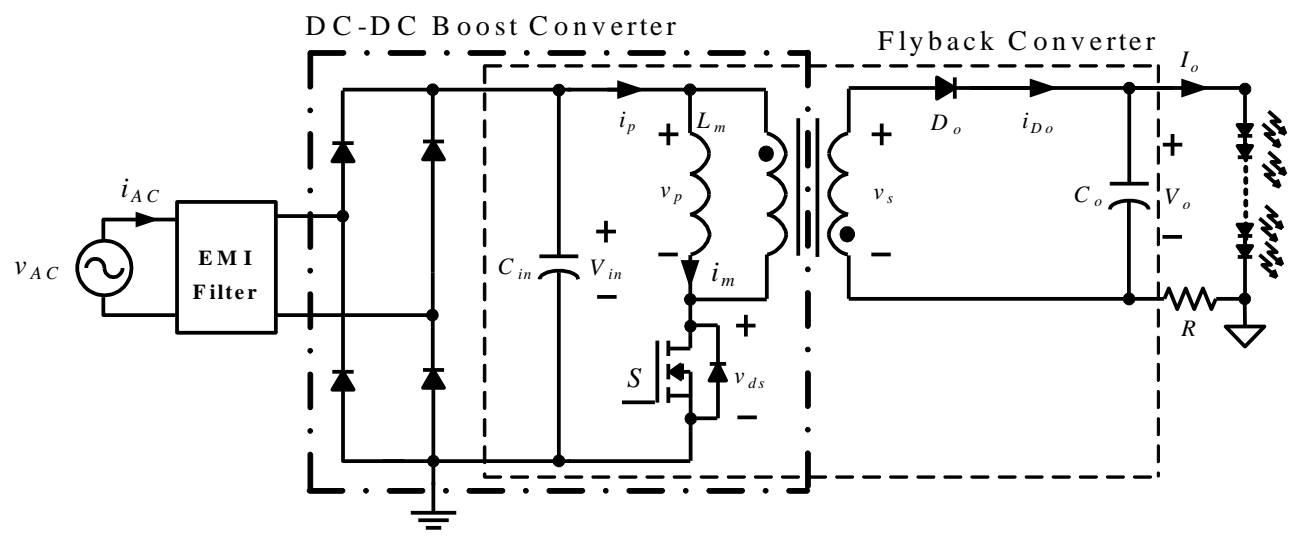

Figure 2 The Main Power Circuit of the proposed Single-stage LED Converter.

Figure 2 shows the main power circuit of the proposed single-stage LED converter, and Figure 3 shows the theoretical waveforms of the key parts of the proposed converter.

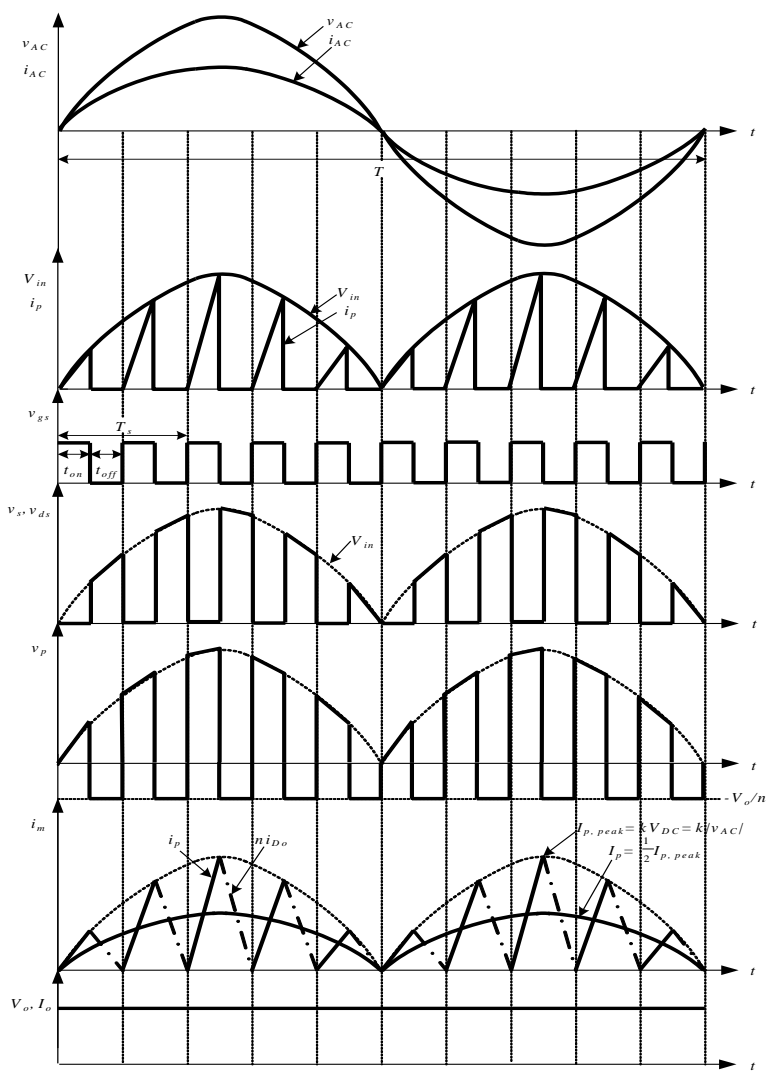

Figure 3 The Theoretical Waveforms of the Key Parts of the proposed Converter 
Also, the proposed converter operates in critical conduction mode (CCM). This is different from the conventional single-stage LED converters that operate ineithercontinuous conduction mode or discontinuous conduction mode. The proposed converter operating with the CCM has an advantage in that it can achieve zero-voltage switching (ZVS) without any additional active snubber circuit. Other advantages include a lower THD of the line current, lower turn-off switching losses, and lower conduction losses due to a smaller peak inductor current when compared with conventional single-stage LED converters [17].

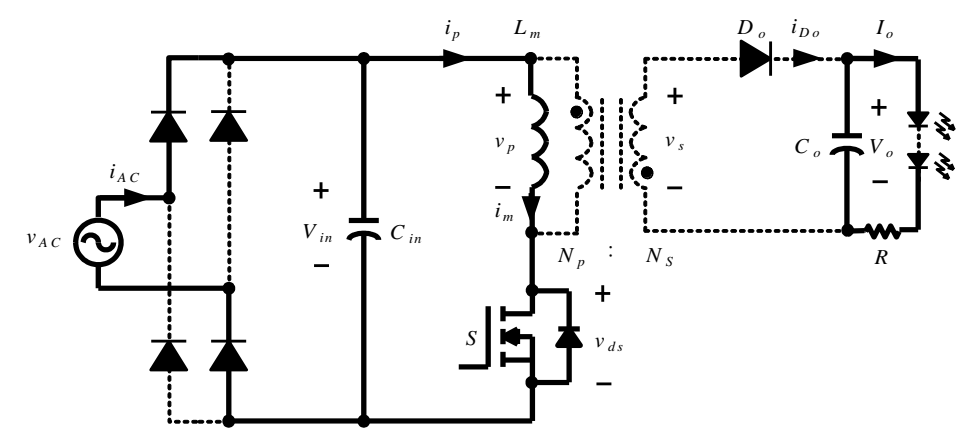

(a) Mode A

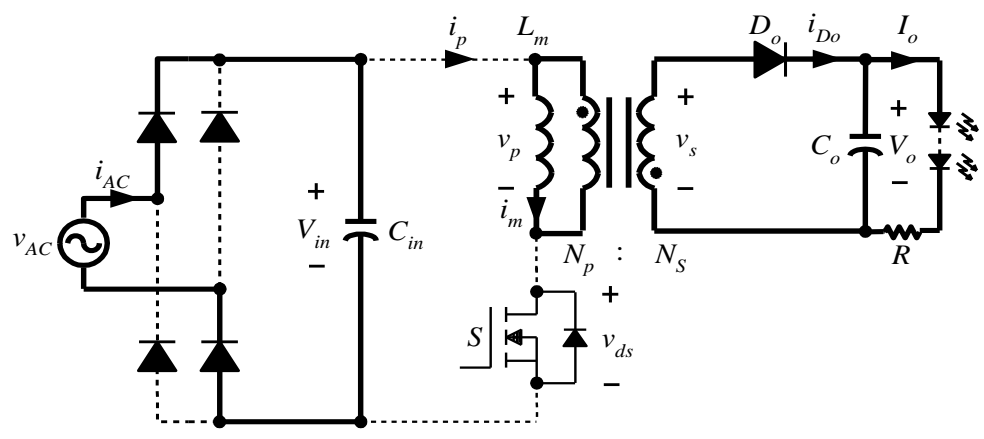

(b) Mode B

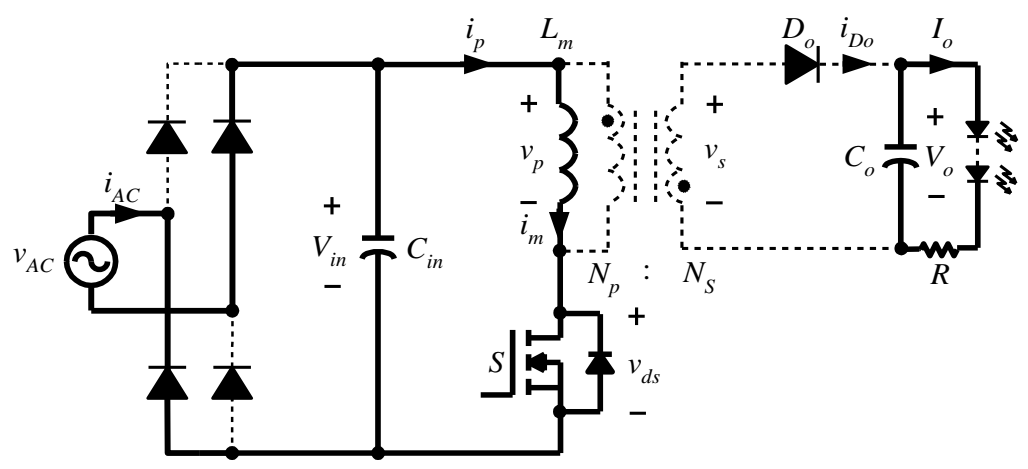

(c) Mode A' 


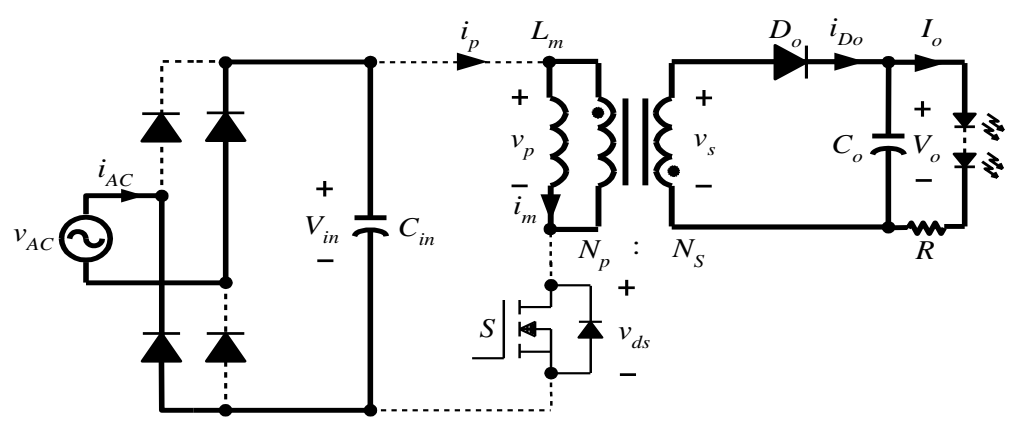

(d) Mode B'

\section{Figure 4 The Operation Modes of the proposed Single-stage LED Converter}

Figure 4 shows the operation modes of the proposed single-stage LED converter, where the bold line represents the conduction line and the dotted line represents the no conduction line. Before the operation mode analysis, the following assumptions are made for the proposed converter:

- The switching frequency of the main power semiconductor switch is much higher than the AC input voltage frequency. Therefore the AC input voltage is considered to be constant at the switching instant.

- The output capacitance $C_{o}$ is large enough that the output voltage $V_{o}$ is a constant value.

- As EMI filter is considered ideal, as a matter of convenience for analysis, it is omitted.

\section{Mode A $\left(t_{0} \sim t_{1}\right)$}

When the switch $S$ turns on at time $t=t_{0}$, this mode starts. The AC input voltage $\left(v_{A C}=V_{m} \sin (2 \pi f) t=V_{m} \sin \omega t\right)$ at a positive half cycle is presented directly through the FB diode rectifier and charges the input capacitor $C_{i n}$, and thus the AC input voltage equals the rectified DC voltage. Then, the primary current $i_{p}$ or switch current that equals the magnetizing current $i_{m}$ through the magnetizing inductance $L_{m}$ and charges it. Therefore the primary current $i_{p}$ is calculated as follows:

$$
\begin{array}{r}
v_{A C}=V_{\text {in }}=v_{p}=L_{m} \frac{d i_{p}}{d t}(1) \\
i_{p}(t)=i_{m}(t)=\frac{1}{L_{m}} \int_{t_{0}}^{t} V_{\text {in }} d \tau .(2)
\end{array}
$$

Asthe AC input voltage is considered to be constant at the switching instant and the proposed converter operates with $\mathrm{CCM}, i_{p}$ is calculated as follows:

$$
i_{p}(t)=i_{m}(t)=\frac{V_{\text {in }}}{L_{m}}\left(t-t_{0}\right)
$$

At time $t=t_{1}$, the primary current $i_{p}$ reaches its peak value $I_{p, p e a k}$ as follows:

$$
I_{p, \text { peak }}=i_{p}\left(t_{1}\right)=i_{m}\left(t_{1}\right)=\frac{V_{\text {in }}}{L_{m}}\left(t_{1}-t_{0}\right) \cong \frac{\Delta t}{L_{m}} V_{m} \sin \omega t_{1}(4)
$$

where $\Delta t=t_{1}-t_{0}$.

In this mode, the secondary output capacitor $C_{o}$ discharges power to the load. When the switch Sturns off at time $t=t_{1}$, this mode ends.

\section{Mode B $\left(t_{1} \sim t_{2}\right)$}

When the switch $S$ turns off at time $t=t_{1}$, this mode starts. The primary current $i_{p}$ becomes zero. If the secondary diode $D_{o}$ is turned on, the primary voltage $v_{p}$ becomes - 
$N_{p} V_{o} / N_{s}$. Then the magnetizing current $i_{m}$ decreases linearly, and the energy in the magnetizing inductance $L_{m}$ is discharged to the transformer secondary. The magnetizing current $i_{m}$ is given as follows:

$$
\begin{array}{r}
\frac{d i_{m}}{d t}=-\frac{V_{o}}{n L_{m}}(5) \\
i_{m}(t)=\frac{1}{L_{m}} \int_{t_{1}}^{t}\left(-\frac{V_{o}}{n}\right) d \tau=-\frac{V_{o}}{n L_{m}}\left(t-t_{1}\right)+I_{p, \text { peak }}(6)
\end{array}
$$

where $n=N_{s} / N_{p}$ is the turn ratio of the transformer.

When the switch $S$ turns on at time $t=t_{2}$, this mode ends.

If the $\mathrm{AC}$ input voltage is in a negative half cycle (modes $\mathrm{A}^{\prime}$ and $\mathrm{B}^{\prime}$ ), the rectified DC input voltage $V_{i n}$ is the same as when the AC input voltage is at a positive half cycle due to the operation of the FB diode rectifier $\left(V_{i n}=\left|v_{A C}\right|\right)$. Therefore, the operations of the converter at a negative half cycle are also the same as in modes $\mathrm{A}$ and $\mathrm{B}$. Thus, the analysis of modes $\mathrm{A}^{\prime}$ and $\mathrm{B}$ 'in a negative half cycle of the $\mathrm{AC}$ input voltage is omitted.

\section{Power Factor Analysis of the Proposed Converter}

In the proposed converter, the primary current $i_{p}$ is conducted by the rectified DC input voltage $V_{\text {in }}$ of the AC input voltage $v_{A C}\left(V_{i n}=\left|v_{A C}\right|\right)$ and is given by (3).The time function type $i_{p, p e a k}(t)$ of the primary peak current $I_{p, p e a k}$ can beapproximated and induced from (4)as follows:

$$
i_{p, p e a k}(t) \cong \frac{\Delta t}{L_{m}} V_{m}|\sin \omega t|=k V_{m}|\sin \omega t|(7)
$$

where $k=\Delta t / L_{m}$, and $\Delta t=t_{1}-t_{0}$, from (4) and figures 3 and 4, is the nominal switch on time that is set by the peripheral circuit of the control IC in figure 1 . The nominal switch on time $\Delta t$ is a constant value and is determined according tothe magnetizing inductance $L_{m}$, the minimum AC input voltage $v_{A C \text {, min }}$, and the maximum output power $P_{o \text {, max }}$.

The average value $I_{p}(t)$ of the primary current $i_{p}$ during the switching period is calculated by the following equation:

$$
I_{p}(t)=\frac{t_{\text {on }}}{T_{s}} \times \frac{1}{2} \times i_{p, p e a k}(t)=\frac{1}{2} D k V_{m}|\sin \omega t|(8)
$$

where $D=t_{o n} / T_{s}$ is the turn-on duty, and the switching period $T_{s}$ is the summation of the switch turn-on time $t_{o n}$ and the switch turn-off time $t_{\text {off }}\left(T_{s}=t_{\text {on }}+t_{\text {off }}\right)$.

However, as shown in figure 1, the switch turn-off time $t_{\text {off }}$ is determined by the operation of the turn-off switching controller in the control IC according to the output of the voltage controller circuit that is a PI (Proportional-Integral) controller. In general, because the PI controller is stable and can make the control object converge to its reference value, the output of the voltage controller is converged to its reference value and becomes nearly constant in a steady state. Therefore the switch turn-off time $t_{\text {off }}$ becomes a nearly constant value, and thus the switching period $T_{s}$ also becomes nearly constant. It follows thatthe turn-on duty ratio $D$ also becomes a nearly constant value, and the average primary current $I_{p}(t)$ in the switching period can be rewritten as follows:

where $K=D k / 2$ is a nearly constant value.

$$
I_{p}(t)=K V_{m}|\sin \omega t|
$$

If the EMI filter at the AC input in figure 1 is connected and operated correctly, from (9) the AC input line current $i_{A C}$ at the $\mathrm{AC}$ line frequency by the FB diode rectifier becomes as follows:

$$
i_{A C}=K V_{m} \sin \omega t(10)
$$

Therefore, it can be known that the AC input voltage and current become in-phase and thus the power factor of the proposed converter becomes unity. 


\section{Design of a Prototype Converter}

To validate the feasibility of the proposed LED converter, a prototype converter was designed with the following specifications:

- AC input voltage: $v_{A C}=90-265 \mathrm{~V}, 60 \mathrm{~Hz}$

- Maximum output power: $P_{o, \max }=32 \mathrm{~W}\left(V_{o}=40 \mathrm{~V}, I_{o, \max }=800 \mathrm{~mA}\right)$

- Nominal minimum switching frequency at a minimum AC input voltage: $f_{s, \min }=50 \mathrm{kHz}$

- Nominal turn-on duty at a maximum output current: $D_{\text {nom }}=0.45$

Asthe switching frequency $f_{s}$ is much higher than the AC input line frequency, the $\mathrm{AC}$ input current $i_{A C}$ during one switching period is assumed to be constant. The maximum AC input current $I_{A C \text {, max }}$ is calculated by the following equation:

$$
I_{A C, \text { max }}=\frac{\sqrt{2} P_{o, \text { max }}}{\eta v_{A C, \text { min }}}=\frac{\sqrt{2} \times 32}{0.82 \times 90}=613 \mathrm{~mA}
$$

where $\eta$ is the design efficiency and is set to $82 \%(\eta=0.82)$ in this design. The maximum switch or primary current $I_{p \text {, max }}$ is given by the following equation:

$$
\begin{array}{r}
I_{A C, \max }=\frac{1}{T} \int_{0}^{D T_{S}} \frac{I_{p, \max }}{D T_{S}} t d t=\frac{D}{2} I_{p, \text { max }} \\
I_{p, \text { max }}=\frac{2}{D} I_{A C, \text { max }}=\frac{2}{0.45} \times 0.613=2.72 \mathrm{~A}
\end{array}
$$

where $D$ is set to the nominal turn-on duty $\left(D=D_{\text {nom }}=0.45\right)$ at maximum output current.

The transformer primary voltage $v_{p}$ is given as follows:

$$
v_{P}=L_{m} \frac{\Delta i}{\Delta t} \cong L_{m} \frac{I_{p, \max }}{D T_{s, \min }} .
$$

Therefore, from (12) and (13), the magnetizing inductance $L_{m}$ is calculated as:

$$
L_{m} \geq \frac{D^{2} \cdot \sqrt{2} v_{A C, \min }}{2 I_{A C, \text { max }} f_{s, \text { min }}}=\frac{0.45^{2} \times \sqrt{2} \times 90}{2 \times 0.613 \times 50 \times 10^{3}} \cong 420 \mu \mathrm{H} .
$$

Then, the magnetizing inductance $L_{m}$ is set as $480 \mu \mathrm{H}$. The turn number of the transformer's primary winding can be calculated using the following physical inductance equation:

$$
L_{m}=\frac{N^{2}}{R_{m}}=\mu_{m} N^{2}
$$

where $R_{m}$ is the reluctance of thetransformer core, and $\mu_{m}$ is the core's permeability or the reciprocal of reluctance $R_{m}$. In this design, $\mu_{m}$ wasselected to be $240 \mathrm{nH} / \mathrm{N}^{2}$, which is the permeability of the transformer core EFD 3030 used in this prototype converter. Thus, the turn number of the transformer's primary winding is calculated as $N_{p}=45$.Also, the turn number of the transformer's secondary winding can be calculated using the voltage-transfer ratio equation of the conventional flyback converter and was selected as $N_{s}=18$. So the turn ratio of the transformer $n$ becomes $n=N_{s} / N_{p}=18 / 45=0.4$.

When the switch $S$ is turned off, voltage stress is applied to the switch due to the flyback operation of the converter. Thus, the maximum voltage stress $V_{d s, \max }$ of the switch $S$ is considered as the following equation:

$$
V_{d s, \text { max }}=\frac{V_{o}}{n}+\sqrt{2} v_{A C, \text { max }}=\frac{40}{0.4}+\sqrt{2} \times 265=475 V(17)
$$

Therefore, the switch $S$ was selected as a 600-V/12-A commercial MOSFET.

In the design of the secondary output diode $D_{o}$, the reverse voltage $V_{D R}$ and forward peak current $I_{D, p e a k}$ of the diode are considered. These specifications of the output diode are calculated by the following equations:

$$
\begin{gathered}
V_{D R}=V_{o}+n \sqrt{2} v_{A C, \text { max }}=40+0.4 \times \sqrt{2} \times 265 \cong 190 \mathrm{~V} \\
I_{D, \text { peak }}=\frac{2}{1-D} I_{o}=\frac{2}{1-0.45} \times 0.8 \cong 2.9 \mathrm{~A}
\end{gathered}
$$

Thus, the diode $D_{o}$ was selected as a $400-\mathrm{V} / 10-\mathrm{A}$ commercial diode. 


\section{Experimental Results}

To validate the feasibility of the proposed LED converter, a prototype converter, based on the design example in Section 4, was constructed and tested.

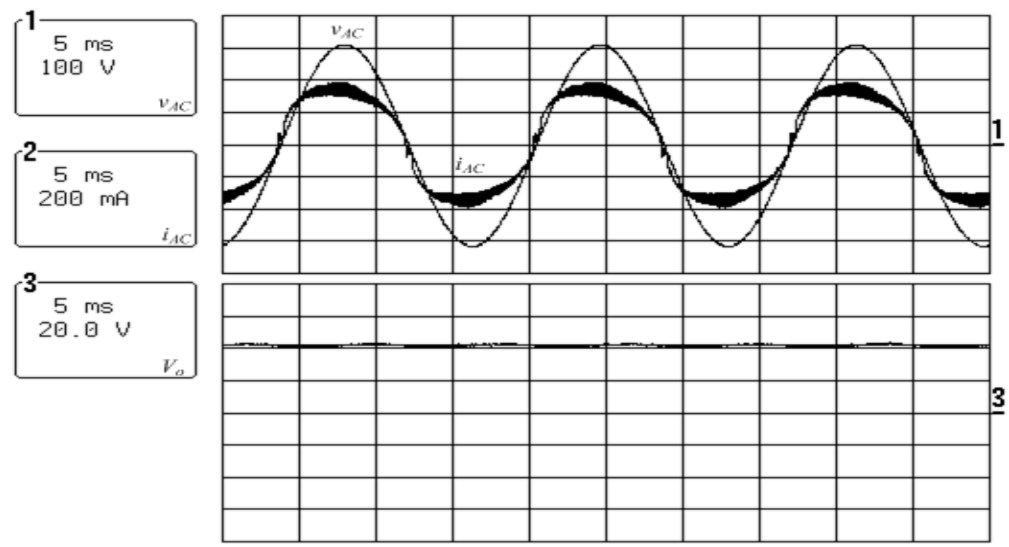

Figure 5 The Experimental Waveforms of the AC Input Voltage and Current, and the DC Output Voltage and Current of the proposed LED Converter

Figure 6 The Experimental Waveforms of the Key Parts of the proposed

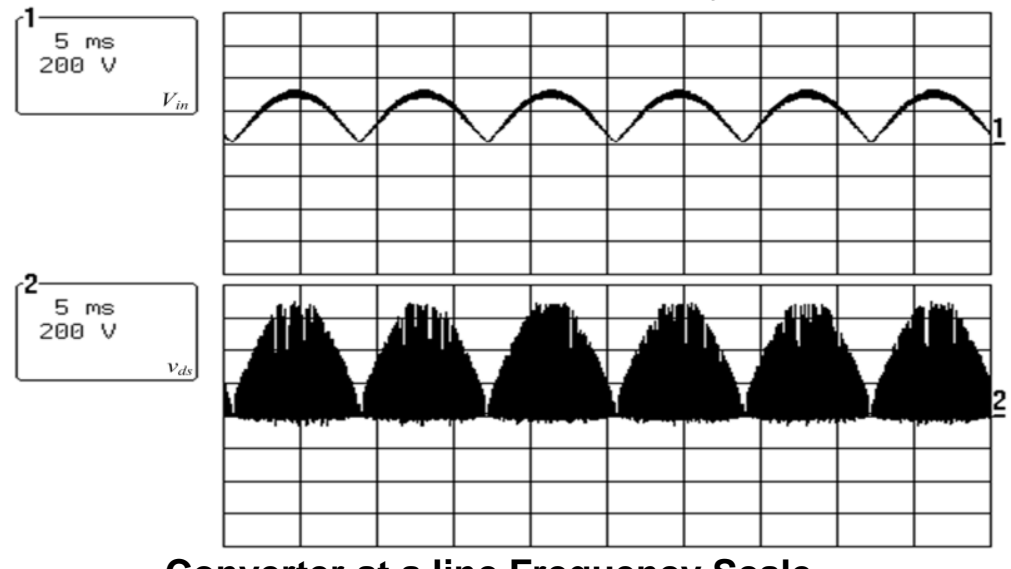

Converter at a line Frequency Scale

Figure 5 shows the experimental waveforms of the AC input voltage and current, and the DC output voltage and current of the proposed LED converter. These waveforms show that the power factor of the proposed converter is nearly unity, and the proposed converter can maintain a constant output voltage and current for constant brightness of an LED.

Figure 6 shows the experimental waveforms of the switch voltage $v_{d s}$ and the rectified DC input voltage $V_{i n}$ of the proposed converter at a line frequency scale. These waveforms show that the control IC with the CCM control function operates very well for driving the proposed flyback converter, and the proposed converter circuit is well designed and operates well.

Figure 7 shows the experimental waveforms of the PWM output $v_{g s}$ of the control IC and the switch voltage $v_{d s}$ of the proposed converter at a switching frequency scale These waveforms show that the control IC of the proposed converter correctly drives the main switch of the proposed converter. 


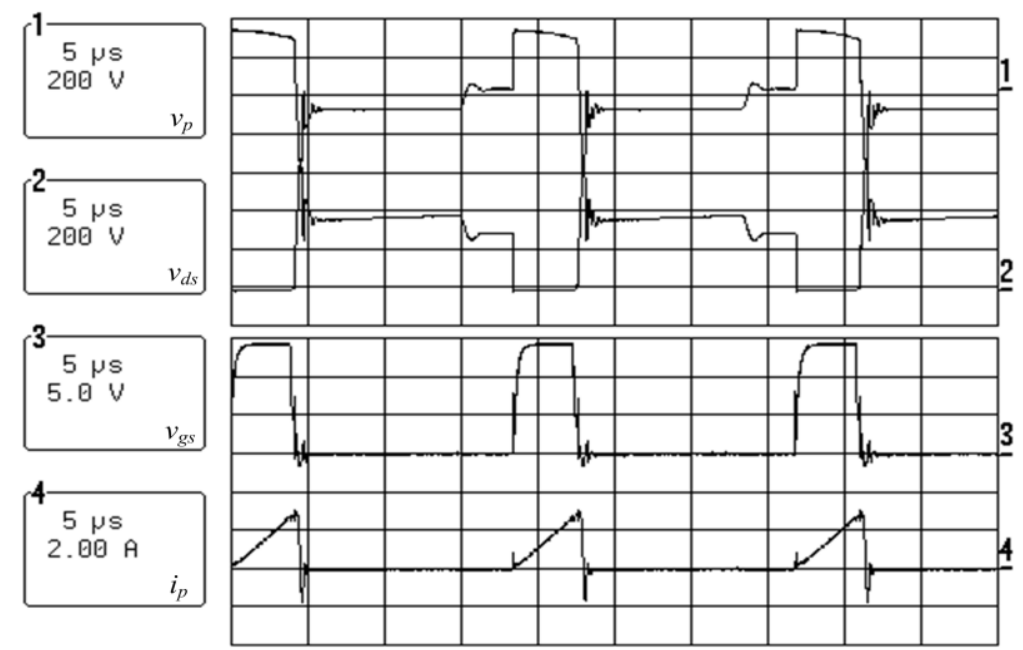
Figure 7 The Experimental Waveforms of the Key Parts of the proposed
Converter at a Switching Frequency Scale

\section{Concluding Remarks}

In this paper, a single-stage LED converter with high power factor was presented. The proposed converter simplifies the power topology using a single-stage converter that mergesa DC-DC boost converter and flyback converter,using this architecturewe can also simplify its control circuit. The control of the proposed converter uses the CCM technique and the fixed on-time voltage control technique. The proposed converter has good performances in terms of high power factor, high efficiency, cost-effectiveness, and constant output voltage/current. In this paper, an operational principle and a prototype design example of the proposed converter were described, briefly, and experimental results of the prototype are shown. A 32-W prototype converter has been built based on the design example and tested to show the feasibility of the proposed converter. The prototype has shown very good performance.

\section{Acknowledgements}

This work was supported by the Soonchunhyang University Research Fund.

\section{References}

[1] M. Doshi and R. Zane, "IEEE Trans. Power Elec.", vol. 25 (2010), pp 7.

[2] B. Lee, H. Kim and C. Rim, "IEEE Trans. Power Elec.", vol. 26 (2011), pp12.

[3] Y. T. Hsieh, B. D. Liu, J. F. Wu and C. L. Fang et.al., "IEEE Trans. Power Elec.”, vol. 27 (2012), pp11.

[4] C. S. Moo, Y. J. Chen and W. C. Yang, "IEEE Trans. Power Elec.”, vol. 27, (2012), pp11.

[5] S. W. Lee and S. Y. Kim, "Int. Jour. of Multimedia and Ubiquitous Engineering", vol. 2, no. 7 (2012).

[6] N. Chen and H. S. H. Chung, "IEEE Trans. Power Elec.", vol. 5, no. 28, (2013).

[7] K. Lee, D. Cha and K. Lee, Int. Jour. of Control and Automation, vol. 2, no. 6, (2013).

[8] J. J. Kang, K. Um, S Yoo and G. S. Choi, et.al., "Int. Jour. of Control and Automation", (2013), pp 2, 6.

[9] X. Xie, M. Ye, Y. Cai and J. Wu, "Proceedings of IEEE Applied Power Electronic Conference and Exposition", Fort Worth, U.S.A., (2011) March 6-11.

[10] P. Athalye, M. Harris and G. Negley, "Proceedings of IEEE Applied Power Electronic Conference and Exposition", Orlando, USA, (2012) March 5-9.

[11] M. Arias, M. F. Diaz, D. G. Lamar, D. Balocco et.al., “IEEE Trans. Power Elec.”, vol. 5, no. 28, (2013).

[12] C. S. Moo, K. H. Lee, H. L. Cheng and W. M. Chen, "IEEE Trans. Ind. Electron", vol. 4, no. 56, (2009).

[13] D. Gacio, J. M. Alonso, A. J. Calleja, J. García et.al., "IEEE Trans. Ind. Electron”, vol. 2, no. 58, (2011). 
[14] Y. C. Li and C. L. Chen, "IEEE Trans. Ind. Electron", vol. 2, no. 59, (2012).

[15] Xie, J. Wang, C. Zhao, Q. Lu and S. Liu, "IEEE Trans. Power Elec.”, vol. 11, no. 27, (2012).

[16] S. C. Moon, G. B. Koo and G. W. Moon, "IEEE Trans. Power Elec.", vol. 8, no. 28, (2013).

[17] K. H. Liu and Y. L. Lin, "In Proceeding of the IEEE Power Electronics Specialists Conference '89", Milwukee, U.S.A., (1989) June 26-29.

\section{Authors}

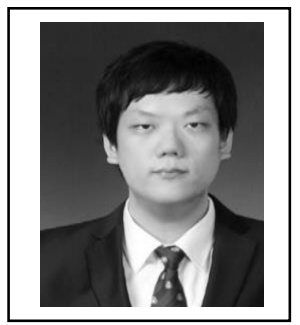

\section{Geun-Yong Park}

Geun-Yong Park received his B.S. degree in Electronic Information Engineering in 2013 from Soonchunhyang University, Korea, where he is currently working toward the M.S. degree. His research interests include DC-DC power converter, AC-DC high frequency inverter, and power conversion for the renewable energy.

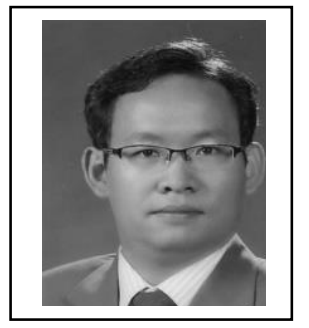

\section{Gang-YoulJeong}

Gang-YoulJeong received his B.S. degree in Electrical Engineering from Yeungnam University, Korea, in 1997, and his M.S. and Ph.D. degrees in Electronic and Electrical Engineering from POSTECH (Pohang University of Science and Technology), Korea, in 1999 and 2002, respectively. He has been an associate professor in Department of Electronic Information Engineering, SoonchunhyangUniversity, Korea. His research interests include DC-DC power converter, AC-DC high frequency inverter, and power conversion for the renewable energy. 